\title{
Combined Removal of an MTBE and BTEX Mixture Using Indigenous Microbe Immobilized on Waste Silica Gel
}

\author{
Fei Xie, Qihong Lu, Renata Alves de Toledo, and Hojae Shim
}

\begin{abstract}
The immobilization system utilizing waste silica gel as matrix was employed for the simultaneous removal of a mixture of BTEX (benzene, toluene, ethylbenzene, $o, m, p$-xylene) and methyl tert-butyl ether (MTBE) from an artificially contaminated water. Pure culture utilizing BTEX as growth substrate while co-metabolizing MTBE was enriched and isolated from the activated sludge sample collected from a regional wastewater treatment plant in Macau SAR, China. The comparison between suspended and immobilized systems was studied to determine the enhanced removal of these contaminants. In immobilized system with $50 \mathrm{mg} / \mathrm{L}$ BTEX and $100 \mathrm{mg} / \mathrm{L}$ MTBE, toluene, benzene, ethylbenzene, and $m, p$-xylene were completely removed while the removal efficiencies of $98.5 \pm 1.7 \%$ and $81.3 \pm 2.2 \%$ were obtained for $o$-xylene and MTBE, respectively. The adsorption kinetics of contaminants on silica gel was also evaluated and the adsorption capacity followed the order of $o$-xylene $>p$-xylene $>m$-xylene $>$ ethylbenzene $>$ benzene $>$ toluene $>$ MTBE. Results from this study suggested that waste silica gel could be a promising waste material for the simultaneous adsorption and bioremoval of BTEX and MTBE from contaminated groundwater.
\end{abstract}

Index Terms-BTEX, immobilization, MTBE, removal, waste silica gel.

\section{INTRODUCTION}

Petroleum-based products are the major sources of energy for industry and daily life. The most toxic components in petroleum products, with potential mutagenic, teratogenic, and carcinogenic activities, include such monoaromatic compounds as benzene, toluene, ethylbenzene, and three isomers (ortho-, meta-, and para-) of xylene, collectively known as BTEX. They are also widely used as industrial solvents for organic synthesis and equipment cleansing-and are easily seep into groundwater [1]. BTEX compounds are of significant environmental concern and are listed as priority pollutants by the United States Environmental Protection Agency (US EPA) because of their toxic and carcinogenic effects on humans [2]. Methyl tert-butyl ether (MTBE) is a petroleum fuel additive commonly used as a fuel oxygenate, promoting more complete combustion of gasoline and consequently decreasing the emission of carbon monoxide

Manuscript received on April 15, 2015; revised June 18, 2015. This work was supported by the University of Macau Multi-Year Research Grant [MYRG204 (Y3-L4)-FST11-SHJ and MYRG2014-00112-FST] and by the Macau Science and Technology Development Fund (FDCT 063/2013/A2).

The authors are with University of Macau, Faculty of Science and Technology, Macau SAR, China (e-mail: xiefei0622@outlook.com, nickylu620@gmail.com, toledora@gmail.com, hjshim@umac.mo). and nitrous oxide [3]. MTBE is frequently found in groundwater together with other gasoline contaminants, with the most prevalent being BTEX [4]. USEPA's Office of Water has concluded that available data are not adequate to estimate potential health risks of MTBE at low exposure levels in drinking water but the data support the conclusion that MTBE is a potential human carcinogen at high doses [2]. Thus, the removal of MTBE and BTEX has become an environmental problem owing to their health risks. The occurrence of co-contamination sites is becoming more often and more researches are focusing on the simultaneous bioremoval of BTEX and MTBE mixture [5], [6]. Previous studies suggested simultaneous bioremoval of BTEX and MTBE occurred when mixed cultures were attached to granular activated carbon particles [7]. On the other hand, MTBE bioremoval was severely inhibited in the presence of ethylbenzene and xylenes using PM1 culture enriched from a compost biofilter [8]. Similar results were obtained where the removal efficiency for MTBE was strongly inhibited by toluene and xylene [9].

The immobilization technology has been receiving increasing attention on the remediation of volatile organic compounds. The use of cells to adhere to the granular activated carbon, sintered glass, or rocks during microbial growth requires long start-up period to remove MTBE efficiently due to the nature of cells and the character of matrices [10]. Encapsulation is another important technique used to immobilize cells. This immobilization process can be performed immediately, and the encapsulated cells often have higher stability and are protected from the direct exposure to toxic compounds in wastewater [11].

Adsorption is another commonly used method for the BTEX and MTBE removal from aqueous solutions. The highest sorption capacity of MTBE in all-silica zeolite has been reported over 95\% (initial concentration, 11,000 $\mu \mathrm{g} / \mathrm{L}$ ) from liquid samples [12]. In comparison, no study utilizing waste materials for the simultaneous adsorption of MTBE and BTEX has been reported. In 2007, 3,190,000 tons of organosilicone were produced worldwide [13]. In organosilicone products, when $\mathrm{R} / \mathrm{Si} \approx 2$ ( $\mathrm{R}$ for organic substituents and $\mathrm{Si}$ for silica), they are known as silica gel. Even though the simultaneous aerobic removal of a mixture of BTEX, cis-1,2-dichloroethylene (cis-DCE), and trichloroethylene (TCE) using an indigenous bacterial isolate identified as Pseudomonas plecoglossicida immobilized on waste scrap tyres was investigated [14], the reutilization technology for the waste silica gel has not been widely used yet and the waste is commonly stored at landfill sites instead 
[15]. To the best of our knowledge, this is the first time the waste silica gel was used as a matrix for the simultaneous adsorption and bioremoval of BTEX and MTBE mixture in aqueous solutions.

In this work, the microorganisms enriched from activated sludge using BTEX as growth substrate were used to co-metabolize MTBE and the waste silica gel was utilized to remove a mixture contaminants. This study aimed to develop an adsorption/biological hybrid process to enhance the removal of mixed organic contaminants (MTBE+BTEX) from aqueous solution by immobilizing microorganisms on the surface of waste silica gel.

\section{MAterials AND Methods}

\section{A. Chemicals and Waste Silica Gel}

Benzene (purity, 99.7\%), toluene (purity, 99\%), ethylbenzene (purity, 99\%), ortho-xylene (purity, 99\%), meta-xylene (purity, 99\%), and para-xylene (purity, 99\%) were purchased from the International Laboratory (USA). MTBE (purity, 99\%) was purchased from Damao Chemical Manufacture (China). The stock standard solutions of BTEX and MTBE were prepared at $10,000 \mathrm{mg} / \mathrm{L}$ each in $\mathrm{N}, \mathrm{N}$-dimethylformamide (DMF) and deionized water, respectively, and were stored at $4^{\circ} \mathrm{C}$ until use.

The waste silica gel was collected from the garbage, autoclaved, cut into small pieces $(0.2 \mathrm{~cm} \times 0.5 \mathrm{~cm} \times 0.5 \mathrm{~cm})$, sonicated for $1 \mathrm{~h}$ in deionized water, and dried in oven $\left(60^{\circ} \mathrm{C}\right)$. Silica gel sample was then ground into powder with a grinder. The amount of silica gel used for the adsorption and the bioremoval experiments was carefully weighed and autoclaved for $20 \min \left(121^{\circ} \mathrm{C}, 103.5 \mathrm{kPa}\right)$ before use.

\section{B. Microbial Culture}

The microbe using BTEX as a growth substrate while removing MTBE through co-metabolism was originally enriched and isolated from activated sludge collected from a regional wastewater treatment plant in Taipa, Macau SAR, China. Toluene $(50 \mathrm{mg} / \mathrm{L}$ unless otherwise stated) was first added as the sole source of carbon in the serum bottles and shaken at $150 \mathrm{rpm}$ and $25^{\circ} \mathrm{C}$. Subculture was done weekly (10\% inoculum size) to a fresh mineral salts medium (MSM) containing (in g/L): $\mathrm{KH}_{2} \mathrm{PO}_{4} 1.0 ; \mathrm{K}_{2} \mathrm{HPO}_{4} 1.0 ; \mathrm{NH}_{4} \mathrm{NO}_{3}$ 1.0; $\mathrm{MgSO}_{4} \cdot 7 \mathrm{H}_{2} \mathrm{O} 0.2 ; \mathrm{Fe}_{2}\left(\mathrm{SO}_{4}\right)_{3} 0.05$; and $\mathrm{CaCO}_{3}$ 0.02. The $\mathrm{pH}$ of the medium was adjusted to 7.0 by the addition of $\mathrm{NaOH}$ $(1.0 \mathrm{~mol} / \mathrm{L})$ or $\mathrm{HNO}_{3}(1.0 \mathrm{~mol} / \mathrm{L})$ solutions. All the apparatus and liquid media were autoclaved for $20 \mathrm{~min}$ at $121^{\circ} \mathrm{C}$ under $103.5 \mathrm{kPa}$ in advance.

\section{Analytical Methods}

The concentrations of BTEX and MTBE were measured on a gas chromatograph (Agilent 6890N, Agilent Technologies Co., Ltd, China) equipped with a flame ionization detector and a capillary column (Agilent HP-5; $30 \mathrm{~m} \times 0.53 \mu \mathrm{m} \times 0.88$ $\mu \mathrm{m})$. The temperatures of injector and detector were $120^{\circ} \mathrm{C}$ and $260^{\circ} \mathrm{C}$, respectively. The initial temperature program for column was $40^{\circ} \mathrm{C}$ and incrementally increased $\left(6^{\circ} \mathrm{C} / \mathrm{min}\right)$ to $110^{\circ} \mathrm{C}$. The optical density (OD) of microbial culture was measured at $600 \mathrm{~nm}$ using a spectrophotometer (DR 2800, Hach Company, USA).

\section{Experimental Set-up}

The experiments were conducted in $160-\mathrm{mL}$ serum bottles covered with stopper ( $90 \%$ teflon/10\% silicone; Ohio Valley Specialty, USA), sealed with aluminum crimp, and inverted to minimize the volatilization of contaminants. BTEX solution $(50 \mathrm{mg} / \mathrm{L})$ was prepared following the ratio of benzene: toluene: ethylbenzene: $o$-xylene: $m$-xylene: $p$-xylene in BTEX at $22.7 \%: 48.3 \%: 4.6 \%: 6.3 \%: 6.9 \%: 11.1 \%$, based on the mass fractions in crude oil, together with MTBE (100 $\mathrm{mg} / \mathrm{L}$ ). Contaminants and different weights of waste silica gel were added into the serum bottles containing $45 \mathrm{~mL}$ of MSM solution, sealed, and shaken. Subsequently, $5 \mathrm{~mL}$ of the early stationary phase inoculum were transferred to each serum bottle. The abiotic loss of the contaminants was measured through the sterile controls without the inoculum and the matrix. All the treatments were incubated in the dark under the desired conditions, in duplicates, and each bottle was measured twice for the liquid phase concentrations of BTEX and MTBE. All the experiments were carried out at $25^{\circ} \mathrm{C}$ and $\mathrm{pH} 7.0$.

\section{E. Adsorption Kinetics of BTEX and MTBE on Silica Gel Surface}

The adsorption kinetics of BTEX and MTBE on silica gel surface was carried out in $160-\mathrm{mL}$ serum bottles. The contaminants were added at the same concentration levels as in the bioremoval experiments (BTEX, $50 \mathrm{mg} / \mathrm{L}$; containing benzene: $11.4 \mathrm{mg} / \mathrm{L}$; toluene: $24.3 \mathrm{mg} / \mathrm{L}$; ethylbenzene: 2.3 $\mathrm{mg} / \mathrm{L} ; o$-xylene: $3.5 \mathrm{mg} / \mathrm{L} ; m$-xylene: $3.2 \mathrm{mg} / \mathrm{L} ;$-xylene: 5.6 $\mathrm{mg} / \mathrm{L}$; MTBE, $100 \mathrm{mg} / \mathrm{L}$ ). Then, $2.0 \mathrm{~g}$ of silica gel pieces were added and the bottles were sealed and shaken. The concentration of each contaminant was measured after $0.5,1$, $2,4,8,12$, and $24 \mathrm{~h}$.

The sorption capacity of adsorbent $\left(\mathrm{q}_{\mathrm{e}}\right)$ was calculated by the equation (1):

$$
q_{e}=V\left(C_{0}-C_{e}\right) / m
$$

where $C_{0}$ and $C_{e}$ are the initial and the equilibrium concentrations $(\mathrm{mg} / \mathrm{L})$, respectively, $m$ is the mass of adsorbent $(\mathrm{g})$, and $V$ is the solution volume (L).

\section{F. Contact Angle}

The silica gel contact angle was measured using a horizontal microscope equipped with a goniometer (Erma Optical, Tokyo, Japan). The silica gel samples of $1.0 \mathrm{~cm}^{2}$ were fixed to the glass slide by the double-sided adhesive tape. Droplets of ultrapure water (Milli-Q®); surface tension, 72.7 $\mathrm{mJ} / \mathrm{m}^{2}$ ) were applied to the surface. The measurements were done at room temperature $\left(25^{\circ} \mathrm{C}\right)$ with $45 \%$ humidity.

\section{RESULTS AND DISCUSSION}

\section{A. Adsorption Studies}

The sorption capacity of individual BTEX compounds and MTBE was further evaluated with each compound present at the same concentration $(50 \mathrm{mg} / \mathrm{L})$. Fig. 1 shows the adsorption capacity of benzene, toluene, ethylbenzene, $o$-xylene, $m$-xylene, $p$-xylene, and MTBE after the adsorption to waste silica gel over time at $25^{\circ} \mathrm{C}, \mathrm{pH} 7.0$, and $150 \mathrm{rpm}$. 
BTEX compounds and MTBE were mainly removed within $12 \mathrm{~h}$ and no further removal was observed, indicating the matrix saturation. The adsorption capacities followed the order of $o$-xylene> $p$-xylene $>m$-xylene $>$ ethylbenzene $>$ benzene $>$ toluene $>$ MTBE. The adsorption capacity for MTBE using waste silica gel $(0.892 \mathrm{mg} / \mathrm{g})$ was higher than the results obtained with granular activated carbon $(0.019 \mathrm{mg} / \mathrm{g})$ [16], suggesting the waste silica gel can be a good material to be applied to the removal of MTBE in contaminated sites. The preferential adsorption of BTEX compounds on silica gel surface suggests the hydrophobic nature of the surface. The favorable adsorption of xylenes and ethylbenzene is due to the higher octanol-water partition coefficient $\left(\mathrm{K}_{\mathrm{OW}}=3.15\right)$ [17]. The hydrophobic nature of silica gel surface was confirmed by the contact angle measurements $\left(105.2^{\circ} \pm 2.5\right)$. According to Yuan and Lee [18], a contact angle higher than $90^{\circ}$ usually indicate the wetting of the surface is not favorable.

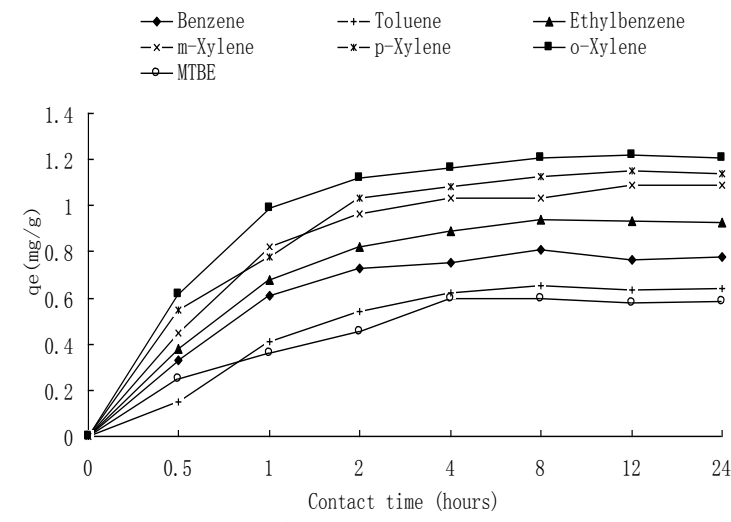

Fig. 1. Adsorption capacity of each BTEX compounds and MTBE over time with $2.0 \mathrm{~g}$ silica gel as adsorbent. Concentration of each contaminant was 50 $\mathrm{mg} / \mathrm{L}$.

The current results were similar with the previous study [19], where the higher adsorption capacity was attributed to the lower water solubility and the higher hydrophobic nature of BTEX contaminants. The adsorption capacity of BTEX was also reported on activated carbon prepared from rice husk [20]. The higher adsorption capacity for xylenes and ethylbenzene was considered due to the increase of methyl groups attached to the aromatic ring. As the side chain length increases, the compound tends to be more hydrophobic and consequently the adsorption increases.

\section{B. Immobilization Studies}
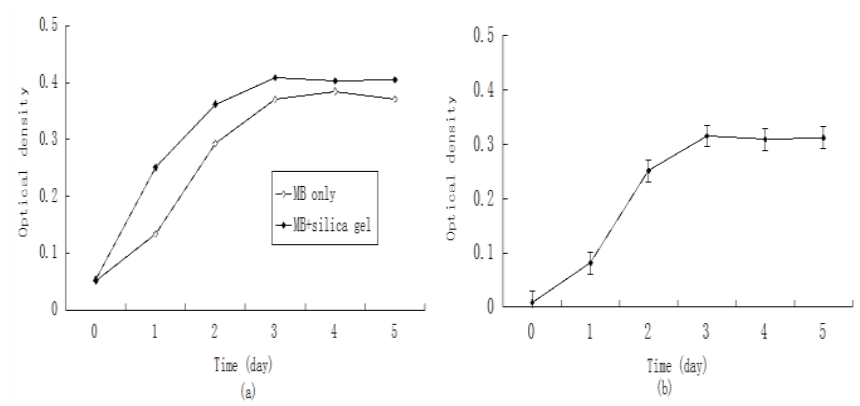

Fig. 2. Microbial growth during 5 days of incubation: (a) MB represents microorganisms only (suspended system), MB + silica gel represents microorganisms with waste silica gel (immobilized system) and (b) The growth curve of microorganisms attached on silica gel with $50 \mathrm{mg} / \mathrm{L} \mathrm{BTEX}$ provided as substrate.
As shown in Fig. 2(a), the growth of microorganisms for the immobilized system using waste silica gel together with microorganisms was faster and better compared to the suspended system containing microorganisms only. To verify the microbial cells were really attached on the matrix, pieces of silica gel used in this experiment were removed from the serum bottle and washed with phosphate buffered saline (PBS) to remove non-attached cells. The matrix was transferred to a bottle with sterilized fresh MSM with BTEX (50 mg/L) provided as the growth substrate. Fig. 2(b) shows the growth curve of microorganisms attached on the silica gel, suggesting the waste silica gel can be used as a matrix to attach microorganisms on the surface and protect microorganisms from toxic environment while improving the contaminant removal efficiency.

The attachment of microbial cells to surfaces is known to depend on a number of factors including Brownian movement, van der Waals attraction, gravitational forces, and surface electrostatic charges [21]. One of the most important factors is the hydrophobicity of the cells. Depending on the type of surface, hydrophobicity of surface can increase the proportion of microorganisms to attachment. Many bacteria attach preferentially to hydrophobic surfaces compared to hydrophilic ones [22]. The identification of bacterial strain used in this study will be done to further evaluate the exact mechanism of cell adsorption on silica gel surface.

TABLE I: REMOVAL EFFICIENCIES FOR INDIVIDUAL COMPOUNDS UNDER DIFFERENT CONDITIONS AFTER 5 DAYS OF INCUBATION USING WASTE SILICA GEL WITH DIFFERENT SURFACE AREA

\begin{tabular}{ccccccc}
\hline $\begin{array}{c}\text { Surface area } \\
\left(\mathrm{cm}^{2}\right)\end{array}$ & $\begin{array}{c}\mathrm{B} \\
(\%)\end{array}$ & $\begin{array}{c}\mathrm{T} \\
(\%)\end{array}$ & $\begin{array}{c}\mathrm{E} \\
(\%)\end{array}$ & $\begin{array}{c}m, p-\mathrm{X} \\
(\%)\end{array}$ & $\begin{array}{c}o-\mathrm{X} \\
(\%)\end{array}$ & $\begin{array}{c}\text { MTBE } \\
(\%)\end{array}$ \\
\hline MB 16.2 & 100 & 100 & 100 & $96.2 \pm 0.4$ & $94.4 \pm 0.4$ & $77.4 \pm 0.5$ \\
MB 19.8 & 100 & 100 & 100 & $99.7 \pm 2.9$ & $95.1 \pm 2.8$ & $78.7 \pm 2.6$ \\
MB Powder & 100 & 100 & 100 & 100 & $98.5 \pm 1.7$ & $81.3 \pm 2.2$ \\
B Powder & $72.2 \pm 1.1$ & $67.2 \pm 0.8$ & $89.1 \pm 0.5$ & $93.6 \pm 0.4$ & $94.8 \pm 1.3$ & $36.1 \pm 1.0$ \\
\hline M & $97.6 \pm 1.3$ & 100 & $99.7 \pm 0.2$ & $93.6 \pm 0.5$ & $78.9 \pm 2.4$ & $31.8 \pm 1.7$ \\
\hline
\end{tabular}

Removal efficiencies are shown in mean value \pm standard deviation. $M$ represents microorganisms only as control; MB represents silica gel together with microorganisms; B represents silica gel only without microorganisms.

At the same weight of waste silica gel $(2.0 \mathrm{~g})$, when immobilization system was employed by using silica gel and isolated microorganisms, the removal efficiencies for each compound were much higher compared to when microorganisms and silica gel were separately used (Table I). More than $98 \%$ of all compounds, except MTBE, were removed within 5 days. As shown in Table I, the greater the surface area provided, the better the removal of both BTEX and MTBE. The highest removal efficiency was achieved when the powdered silica gel was used, due to the higher surface area available for the adsorption of microorganisms as well as for the microbial immobilization. The removal efficiencies obtained in the current work for the suspended system were higher compared to previous study (benzene $44.1 \%$; toluene $51.1 \%$; ethylbenzene $26.1 \%$; $o$-xylene $20.6 \%$; $m, p$-xylene $16.3 \%$; MTBE $17.8 \%$ ) [5]. The utilization of waste silica gel as the immobilization matrix to attach microorganisms was successfully employed, as a hybrid technology, for the simultaneous removal of BTEX and MTBE mixture. The results obtained suggest the waste silica 
gel can be successfully used as a matrix to immobilize microorganisms while simultaneously adsorbing contaminants.

\section{CONCLUSION}

A pure culture isolated from activated sludge demonstrates its ability to remove BTEX as a carbon source while co-metabolizes MTBE. To improve the removal efficiency for each contaminant in mixture, especially for MTBE, waste silica gel was successfully used as an immobilized matrix to attach microorganisms on the surface. The results obtained suggest the waste silica gel is a good candidate to enhance the simultaneous removal of BTEX and MTBE, owing to its remarkable adsorption properties as well as the capability to immobilize microorganisms. The developed hybrid technology using waste silica gel could be used in the removal of BTEX and MTBE mixture from contaminated groundwater.

\section{REFERENCES}

[1] J. Li, R. A. Toledo, J. Chung, and H. Shim, "Removal of mixture of cis-1,2-dichloroethylene/trichloroethylene/benzene, toluene, ethylbenzene, and xylenes from contaminated soil by Pseudomonas plecoglossicida," J. Chem. Technol. Biotechnol., vol. 89, pp. 1934-1940, December 2013

[2] US EPA (US Environmental Protection Agency), Drinking Water Advisory: Consumer Acceptability Advice and Health Effects Analysis on Methyl Tertiary-Butyl Ether (MTBE), 1997.

[3] I. Levchuk, A. Bhatnagar, and M. Sillanpää, "Overview of technologies for removal of methyl tert-butyl ether (MTBE) from water," Sci. Total Environ., vol. 476-477, pp. 415-433, January 2014.

[4] A. M. Happel, E. H. Beckenbach, and R. U. Halden, "An evaluation of MTBE impacts to California groundwater resources," Lawrence Livermore National Laboratory, UCRL-AR-130897, 1998.

[5] S. C. Chen, C. S. Chen, K. V. Zhan, K. H. Yang, C. C. Chien, B. S. Shieh, and W. M. Chen, "Biodegradation of methyl tert-butyl ether (MTBE) by Enterobacter sp. NKNU02," J. Hazard. Mater., vol. 186, pp. 1744-1750, February 2011.

[6] K. Chen, Y. Chang, and S. Huang, "Biodegradation potential of MTBE and BTEX under aerobic, nitrate reducing, and methanogenic conditions at a gasoline-contaminated site," Desalination and Water Treatment, vol. 48, pp. 1-3, November 2012.

[7] A. Pruden and M. Suidan, "Effect of benzene, toluene, ethylbenzene, and $p$-xylene (BTEX) mixture on biodegradation of methyl tert-butyl ether (MTBE) and tert-butyl alcohol (TBA) by pure culture UC1," Biodegradation, vol. 15, pp. 213-227, August 2004.

[8] R. A. Deeb, J. Y. Hu, J. R. Hanson, K. Scow, and L. Cohen, "Substrate interactions in BTEX and MTBE mixtures by an MTBE-degrading isolate," Environ. Sci. Technol., vol. 35, pp. 312-317, December 2000.

[9] X. Wang and M. A. Deshusses, "Biotreatment of groundwater contaminated with MTBE: Interaction of common environmental co-contaminants," Biodegradation, vol. 18, pp. 37-50, February 2007.

[10] D. Chen, J. Chen, W. Zhong, Z. Cheng, and D. Z. Chen, "Degradation of methyl tert-butyl ether by gel immobilized Methylibium petroleiphilum PM1," Bioresour. Technol., vol. 99, pp. 4702-4708, July 2008.

[11] M. Naito, T. Kawamoto, K. Fujino, M. Kobayashi, K. Maruhashi, and A. Tanaka, "Long-term repeated biodesulfurization by immobilized Rhodococcus erythropolis KA2-5-1 cells," Appl. Microbiol. Biotechnol., vol. 55, pp. 374-378, April 2001.

[12] S. Li, V. A. Tuan, R. D. Noble, and A. J. L. Falconer, "MTBE adsorption on all-silica $\beta$ zeolite," Environ. Sci. Technol., vol. 37, pp. 4007-4010, August 2003.

[13] X. Pu, "Current situation and trend of development of organic silicon industry in domestic and overseas," Chem. Ind., vol. 26, pp. 39-46, 2008.
[14] Q. Lu, R. A. Toledo, F. Xie, J. Li, and H. Shim, "Combined removal of a BTEX, TCE, and cis-DCE mixture using Pseudomonas sp. immobilized on scrap tyres," Environ. Sci. Pollut. Res., May 2015.

[15] D. Vaičiukyniene, V. Vaitkevičius, A. Kantautas, and V. Sasnauskas, "Utilization of by-product waste silica in concrete-based materials," Mat. Res., vol. 15, pp. 561-567. July 2012.

[16] S. G. Huling, S. Ko, S. Park, and E. Kan, "Persulfate oxidation of MTBE and chloroform-spent granular activated carbon," J. Hazard. Mater, vol. 192, pp. 1484-1490, September 2011.

[17] J. M. Ranck, R. S. Bowman, J. L Weeber, L. E. Katz, and E. J. Sullivan, "BTEX removal from produced water using surfactant-modified zeolite," J. Environ. Eng., vol. 131, pp. 434-442, March 2005.

[18] Y. Yuan and T. R. Lee, "Contact angle and wetting properties," in Surface Science Techniques, G. Bracco, B. Holst, eds., vol. 51, Berlin Springer-Verlag, 2013, pp. 3-34.

[19] W. Zhang, W. Ding, and W. Ying, "Biological activated carbon treatment for removing BTEX from groundwater," J. Environ. Eng., vol. 139, pp. 1246-1254, October 2013.

[20] S. M. Yakout and A. A. M. Daifullah, "Adsorption/desorption of BTEX on activated carbon prepared from rice husk," Desalin. Water Treat, vol. 52, pp. 4485-4491, June 2014.

[21] A. Krasowska and K. Singler, "How microorganisms use hydrophobicity and what does this mean for human needs," Front. Cell Infect. Microbial, vol. 4, pp. 1-7, August 2014.

[22] H. Pringle and M. Fletcher, "Influence of substratum wettability on attachment of freshwater bacteria to solid surfaces," Appl. Environ. Microbiol, vol. 45, pp. 811-817, March 1983.

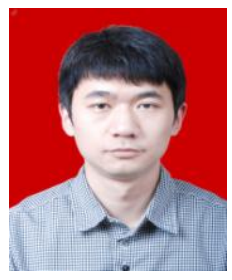

Xie Fei was born in Taiyuan, China. He obtained the bachelor degree in safety engineering in 2013 from Taiyuan Institute of Technology, China. Currently, he is working for his master degree at University of Macau in environmental engineering area.

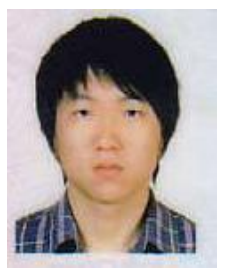

Qihong Lu was born in Jingzhou, Hubei, China. He obtained the bachelor degree in chemical engineering in 2009 from South China University of Technology, China. He earned the master degree in environmenta engineering from University of Macau, Macau SAR, China. Now he is working for his $\mathrm{PhD}$ degree at University of Macau in environmental engineering area.

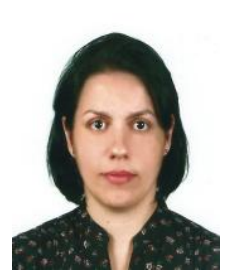

Renata Alves de Toledo was born in São Paulo state, Brazil. She obtained her bachelor degree in chemistry in 1999 from São Carlos Institute of Chemistry, University of São Paulo, Brazil. She earned the master (2002) and the PhD (2006) degrees in analytical chemistry from the same university. She worked as a postdoctoral at Brazilian Organization for Agricultural Research (EMBRAPA, São Carlos, Brazil) from 2006 to 2008. Currently, she is a postdoctoral fellow in environmental area at University of Macau, Faculty of Science and Technology.

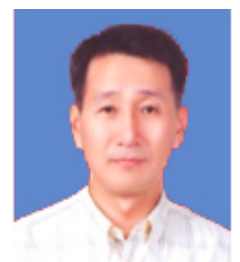

Hojae Shim was originally from Korea, who worked as a post-doctor at Ohio State University (1.5 years) and University of Connecticut (1 year) in U.S., followed by as a research professor at Hanyang University in Korea for 3 years. He has been teaching at University of Macau, Department of Civil and Environmental Engineering since 2003, in charge of Environmental Biotechnology Laboratory. He has completed many research projects funded by the Korean Ministry of Environment and the University of Macau Multi-Year Research Grant/the Macau Science and Technology Development Fund, as a principal investigator (PI)/co-PI, in cooperation with Tongji University and Institute of Urban Environment/Research Center for Eco-Environmental Sciences under Chinese Academy of Sciences in China. His main research areas in environmental biotechnology include: a) bioremediation/rhizoremediation of soil and groundwater contaminated with petroleum and chlorinated compounds, b) biological wastewater treatment and sludge treatment, c) biodiesel/biogas production from waste (water). 